\title{
The Role of Social Support in the Association Between Dependency and the Important Risk Factors Among Elderly: A Cross-sectional Study Based on Baseline Data From Aehrr Project
}

PinYu Cui

Zhejiang University

Yuan Chen

Zhejiang University

YaXing Li

Zhejiang University

Nuremaguli WaiLi

Zhejiang University

Ying Li ( $\square$ liying2012@zju.edu.cn )

Department of Social Medicine, School of Public Health, Zhejiang University, 866 Yu-hang-tang Road, Hangzhou, Zhejiang, 310058, China.

Research article

Keywords: personality disorders, social support, mental health, epidemiology

Posted Date: August 31st, 2020

DOI: https://doi.org/10.21203/rs.3.rs-55456/v1

License: (c) (i) This work is licensed under a Creative Commons Attribution 4.0 International License.

Read Full License 


\section{Abstract}

\section{Background}

Dependence is a common mental disorder among the elderly increases with increasing age \and can lead to serious health problems. This study aimed to assess the association between social resources and dependency, and explored the effect of social support on modification of important risk factors for dependency among elderly.

\section{Method}

The present study was a population-based cross-sectional study. A total of 950 participants aged $\geq 60$ years were selected using a complex multistage sampling design from 22 locations in China. All data were collected using questionnaires by face-to-face interviews. The dependency was assessed using the standardized Minnesota Multiphasic Personality Inventory-II, and the social resource was assessed using the questionnaires of Older American Resources and Services (OARS) in Chinese version. The logistic regression analysis was used to evaluate the association between dependency and social resources. The analysis of covariance was performed to evaluate the effect of social support on modification of important risk factors for dependency.

\section{Results}

A total of 913 participants were included in the analysis, and $10.3 \%$ of males and $14.4 \%$ of females were identified as dependency. The results of logistic regression analysis showed that a significant negative association between the levels of social resource and dependency. The odds ratio was $0.78(95 \% \mathrm{Cl}$, 0.73-0.84) after adjusting for important confounding factors. The results of analysis of covariance showed the differences in the mean dependency score between different chronic disease status and social support level.

\section{Conclusion}

The levels of social resources were negatively associated with dependency. Our results suggest that the social support had both a direct effect on dependency and an indirect effect through modifying chronic disease status and individual income.

\section{Background}

Aging is accompanied with an increasing number of health problems and challenges for individuals, society, and health systems. A common concern is that the prevalence of chronic diseases, the need for health and social services, and dependency among the elderly increases with increasing life expectancy $[1,2]$. 
Dependency is a personality disorder in which people are highly dependent on others to meet their emotional and physical needs and results in the gradual loss of autonomy $[3,4]$. Dependency can lead to disability and premature functional dependence and is associated with length of hospital stay, increased healthcare costs, and adverse effects on the physical and mental health of caregivers $[5,6]$.

Epidemiological studies showed that dependency is associated with a variety of behavioral problems and leads to increases in consequences of ill health such as depression, suicide, heart disease and all-cause mortality $[7,8]$.

The prevalence of dependency is high among the elderly worldwide [9]. In traditional countries, the family is considered their major healthcare resource. However, with the change in the world population structure and social economy, the family can no longer be considered the major healthcare resource [10]. A previous research indicated that socially disadvantaged elderly and those without family members to provide unpaid care and sufficient income might fall into dependency early [11]. Another work reported that the elderly living alone have low levels of dependency. The inconsistent results of the two studies are not well understood. However, a recent study suggests that the relationship between dependency or health status and provision of support is complicated and by no means a simple one.

In fact, most community care policies for the elderly have increased dependency on the family for caregiving. Thus, family caregiving has become an expanding phenomenon [12]. Even in resource-rich countries, the demand for homecare services has also increased. Alternative services have been developed to enable people to become independent in terms of personal care activities if possible or could be provided through the improvement of services $[13,14]$. Such services may enhance independence, reduce dependency, and lead to cost reduction; however, the validity of these various assumptions has not been examined yet. For the elderly, a worldwide a key challenge is the decline in the traditional sources of formal and informal care [15].

Exploring effective methods to reduce and delay the dependency of the elderly is a priority problem aim to alleviate the shortage of healthcare resources and the increase for need caused by rapid aging. In this study, the association between dependency and the level of social resources will be clarified. To the best of our knowledge, the complex relationship between dependency or chronic disease status and provision of support has not been elucidated through complete data analysis. Therefore, the research questions were addressed in the current study. Our aim is to provide evidence for further study and development of effective intervention strategies to reduce dependency among the elderly.

\section{Methods}

\section{Study design}

This work adopted a cross-sectional study design nested in the project "Accessibility Evaluation of Health-Related Resources for the Elderly (AEHRR). All participants provided written informed consent before participation. The study was approved by the institutional review board at the School of Public Health, Zhejiang University. 


\section{Setting and participants}

A total of 950 general residents aged $\geq 60$ years were selected using a complex multistage sampling design. Sampling was conducted in 22 locations (urban/rural) in four provinces (Zhejiang, Heilongjiang, Xinjiang, and Chongqing) in China from 2019 to 2020. A population-based survey was conducted to assess the health and health-related resources of accessibility from multiple aspects: social, economic, behavioral and psychological, medical, and environmental among the general elderly. Subjects who were unable to complete the questionnaire were excluded.

\section{Data collection}

Data were collected using questionnaires provided during face-to-face interviews. Part of the family interviews was conducted by investigators who were guided by villagers proficient in the local language. The questionnaires consisted of 9 parts comprising 428 items. The main contents included the following: social resources, medical resources, community health service resources, psychological resources, environmental resources, and activities involving daily living assessment.

\section{Measurements}

Dependency scale was validated as a measure of dependency from the standardized Minnesota Multiphasic Personality Inventory-II in Chinese version. The dependency scale comprised 57 items. The raw score was converted into a standardized T-score. Dependency is defined as the standardized T-score greater than or equal to 60 points. Social resource status was assessed using the Chinese version questionnaires of Older American Resources and Services (OARS). The OARS social resource scale included three dimensions: social interaction, availability of social support and practical assistance, and interpersonal relation. The ratings were summed to yield a total score. High scores indicate high levels of social resource. Two potential variables were distinguished with four questions for the availability of social support and family assistance. The availability of social support was measured using two questions as follows: "Is there someone who would give you any help at all if you were sick or disabled?" and "Do you find yourself feeling lonely?" The family assistance included two questions: "Who do you live with at present?" and "Do you see your relatives and friends as often as you want to or not?"

\section{Statistical analysis}

Statistical analysis was restricted to the 913 participants with complete questionnaires and dependency assessment data. Descriptive statistics were used to describe the general characteristics of the study participants.

The logistic regression model was used to evaluate the association between dependency and social resources. The dependency score was treated as a binary variable. If the participant's T-score of dependency scale is greater than or equal to 60 points, then they will be regarded as a dependent individual in the binary dependent variable of the logistic regression model expressed by " 1 "; otherwise, 
" 0 " if their score is lower than 60 points. As a continuous variable, the score of social resources is the sum of the scores of the three dimensions. High scores are considered to have more social resources.

In multiple linear regression analysis, the dependency score was included in the analyses as a continuous dependent variable. A separate standardized estimate was calculated for the four dimensions of social resources to evaluate the association between social resource level and dependency score from different dimensions. The scores were adjusted for age, gender, education level, marital status, individual income, smoking status, alcohol use, physical activity, and chronic disease status.

Analysis of covariance (ANCOVA) was performed two times by using the general linear model (GLM) procedure. In model 1, the change in dependency score was evaluated based on the four categories. The four categories were derived according to different chronic disease status and social support. The four categories were represented by groups. Group 1 is the reference group and consists of individuals who reported one or more chronic diseases and without social support. Group 2 consists of individuals without chronic diseases but without social support. Group 3 consists of individuals with chronic diseases and social support. Group 4 consists of individuals without chronic diseases but with social support. Variance homogeneity test and normality test were performed. The mean and standard error were calculated for dependency score among the four groups. The linear trend was assessed using a general linear model. Comparisons were conducted among the four groups by using an $\mathrm{F}$ test with a significance level of 0.05. All analyses were performed using SAS for Windows (version 9.4).

\section{Results}

The demographic characteristics of the study participants are shown in Table 1. The mean age of the participants was 68.5 years. Also, $10.3 \%$ of males and $14.4 \%$ of females were categorized as dependency in accordance with their response on the 57 -item dependency scale.

Table 2 shows the significant negative association between the levels of social resource and dependency by binary logistic regression analyses. After adjusting for age, gender, chronic disease status, individual income, education level, physical activity, marital status, smoking and alcohol use, the odds ratio was $0.78(95 \% \mathrm{Cl}, 0.73-0.84), p<0.001$.

The $\beta$ coefficients of social resources score in different dimensions and important independent variables for dependency score are shown in Table 3. The levels of social support were most strongly negatively associated with dependency score compared with those of the other three dimensions of social resources, such as social communication, family support, and interpersonal relationship in the multiple regression $(p<0.001)$. The results of multiple linear regression analysis also showed that dependency score was significantly negatively associated with the individual income, education level, and physical activity but positively associated with the chronic disease status. The difference in the dependency score between males and females was significant. The association with dependency among males was significant than among women. 
The differences in the mean dependency score between different chronic disease status and social support level are shown in Table 4. Group 2 (without chronic disease and without social support) had lower dependency score than group 1 (chronic disease and without social support). Group 3 (with chronic disease and with social support) had lower dependency score than group 2. Group 4 (without chronic disease and with social support) had lower dependency score than group 3. The test for linear trend of mean was significant. Similar results were obtained in other covariance analyses. Groups 1 (low income and without social support), 2 (high income and without social support), 3 (low income and with social support), and 4 (high income and with social support) had gradually decreasing mean dependency scores, resulting in a significant linear trend.

\section{Discussion}

In this study, the association between social resources and dependency among the elderly was explored. The results of logistic regression analyses showed that the levels of social resources were negatively associated with dependency scale. In the multiple linear regression analysis, the high levels of social support were significantly associated with low levels of dependency.

In the Chinese version of OARS, the availability of social support and practical assistance on one dimension of social resources was divided into two parts: social support and family support. This model is similar to the measurement scale of social resources developed in China, and its reliability and validity have been confirmed and widely used in other studies [16,17]. Compared with the levels of family support, the levels of social support were more significant and negatively associated with dependency. The present results can be partly supported by previous findings [18]. In some Asian countries, the elderly are highly respected in traditional societies and are living with close relatives [19]. They always receive care from their children or other family members when they suffer from diseases or disability. With the change in the socio-economic and population structures, the elderly have lost their traditional role in the family in China and some other countries of the world $[20,21]$. This traditional resource, that is, the formal and unpaid care provided by the family to support the elderly living at home and long-term residential care, will decline in China and other countries [22,23]. The projected decline may affect the social care budgets and hospital discharge directly or indirectly and is a key challenge for aging societies worldwide.

Other studies have shown that dependency will have a considerable effect on families and those who provide care [24]. Many of the elderly consider that the responsibility for care should be with the family rather than with the state. However, increasing numbers of single-person households and divorces, geographically disparate families, increasing number of female employment, and extended working life will make it difficult for such families to provide elderly care in the future [25]. This scenario is not only observed in traditional and high-income countries but also worldwide. In England, local authorities have tightened their eligibility criteria for publicly funded care, and the elderly with substantial savings or incomes will be required to pay for their care privately or unpaid care from their family. The form of care provision leads to considerable negative effects on the carer's health, and as the carers are often young, their ability to remain in workforce will also be affected. 
Recent study has emphasized that the elderly often spend many years in a state of dependency and these elderly are now more live in the community. The number of care homes has decreased over the past two decades, and an increasing number of the elderly choose to live at home in China. However, the prevalence of dependency continuously increases due to population aging, chronic health conditions, and change in social and economic landscapes [26,27]. The elderly will have complex care needs that require sustained input from family carers or community health or social services to support independent living. The results of our study suggest that the levels of high social support are more significantly negatively associated with dependency compared with family support.

To the best of our knowledge, only few studies have reported that chronic diseases and income levels are associated with dependency [28]. A longitudinal study reported that dependency occurs early in the socially disadvantaged [29]. In the present work, the dependency scores were positively associated with chronic disease status and negatively associated with individual income. Analysis of the association between dependency and social support, chronic disease status, and individual income showed that those with social support and without chronic disease had the lowest dependency score. Moreover, those who suffer from chronic diseases but receive social support had lower dependency score compared with those without chronic disease but receive poor social support. The highest dependency score was observed among those who had low income and poor social support. Compared with those who had a high income and poor social support, those who had a lower income but had high levels of social support show a lower dependency score. These results suggest that a high level of social support can modify the effects of chronic disease status and low income on dependency, thereby reducing the risk of developing dependency.

A recent study shows that dependency is independently and significantly associated with direct cost of medical, social, informal, and total care costs [30]. Effective interventions that reduce patient dependence on caregivers may be associated with remarkable reduction in direct cost of medical, social, informal, and total care costs. Furthermore, other study found that increased dependency has high incidence and there is relatively little in the way of from the statutory community services. Dependency is probably widely under recognized in related management departments and receives inadequate action after it is recognized. Therefore, understanding how social resource availability affects elderly health profiles results in the change in dependency level, reduces dependency-related total costs, and helps in developing intervention strategies and policies.

Limited studies have been conducted on the association between dependency that affects personal autonomy with health status and social support among the elderly. In the present study, the risk factors related to dependency and the effects of social support on dependency score among individuals with or without chronic diseases were investigated. High levels of social support are associated with reducing dependency and increasing personal autonomy among the elderly. These results are essential to plan health and social care provision and the projection of future needs for services. 
Family support is a major factor in maintaining elderly functions and has been accepted generally. The functions most commonly lost, such as shopping, cooking, and doing housework, while inessential for an elderly living with children, spouse, or relative, may be crucial for an isolated elderly living alone. Other studies have shown that such elderly are likely to become dependent. Therefore, our findings suggest that the provision of appropriate services, such as home help and care through the social support system whether directly or indirectly, may reduce the dependency and delay or prevent the need for receiving support and care among the elderly.

This study has several limitations. First, this work adopted a cross-sectional design; thus, we could only determine the association between social resources and dependency but not causality. Although we conducted ANCOVA by using GLM to evaluate the change in dependency score based on the four categories and found a significant linear trend, the precise causal relations could not be assessed. However, theoretical justifications for the causal directions were provided in support of the relationships posited in the ANCOVA model by the subgroup. In further studies, a longitudinal study design is needed to clarify the possible causality.

\section{Conclusions}

the study identified the association between poor social support with increased risk of dependency. The findings provide preliminary evidence for the direct and indirect effects of social support on dependency. Furthermore, social support has an indirect effect on dependency mainly by modifying chronic disease status and individual income. This work represents a preliminary undertaking; however, further studies are needed to explore effective social support strategies for reducing or delaying dependency among the elderly.

\section{List Of Abbreviations}

AEHRR: Accessibility Evaluation of Health-Related Resources for the Elderly

OARS: Older American Resources and Services

ANCOVA: Analysis of covariance

GLM: General linear model

\section{Declarations}

\section{Ethics approval and consent to participate}

All participants provided written informed consent before participation. The study was approved by the institutional review board at the School of Public Health, Zhejiang University (No: ZGL201909-10). 
Not applicable.

\section{Availability of data and materials}

The datasets used and/or analyzed during the current study are available from the corresponding author on reasonable request, and the questionnaire for this study that has been uploaded as a supplementary file.

\section{Competing interests}

The authors declare no conflict of interest.

\section{Founding}

This work was supported by the basic public welfare project of Zhejiang Province (LGF19H260012), and in part by WeiJiang Special Foundation, Zhejiang University School of Public Health.

\section{Authors' contributions}

In this paper, YL and PYC were the principal investigators and involved in the study design and conception, manuscript preparation. YC, YXL and NWL performed data collection and analysis. All authors read and approved the final manuscript.

\section{Acknowledgements}

Not applicable.

\section{References}

1. Muennig PA, Glied SA. What changes in survival rates tell us about US health care. Health Affair 2010; 29: 2105-13.

2. Gulley SP, Rasch EK, Chan L. Ongoing coverage for ongoing care: access, utilization, and out-ofpocket spending among uninsured working-aged adults with chronic health care needs. Am J Public Health 2011; 101: 368-75.

3. Bornstein RF. Illuminating a neglected clinical issue: societal costs of interpersonal dependency and dependent personality disorder. J Clin Psychol 2012; 68: 766-81.

4. Morgan TA, Clark LA. Dependent Personality (Disorder). Encyclopedia of Human Behavior 2012: 674-81.

5. Tabali M, Ostermann T, Jeschke E, Dassen T, Heinze C. Does the care dependency of nursing home residents influence their health-related quality of life?-A cross-sectional study. Health Qual Life Outcomes 2013. doi: 10.1186/1477-7525-11-41

6. Abad-Corpa E, González-Gil T, Barderas-Manchado AM, et al. Research protocol: a synthesis of qualitative studies on the process of adaptation to dependency in elderly persons and their families. 
BMC Geriatr 2010. doi: 10.1186/1471-2318-10-58

7. Barbareschi G, Sanderman R, Kempen GI, Ranchor AV. Socioeconomic status and the course of quality of life in older patients with coronary heart disease. Int J Behav Med 2009; 16: 197-204.

8. Acosta D, Rottbeck R, Rodríguez G, Ferri CP, Prince MJ. The epidemiology of dependency among urban-dwelling older people in the Dominican Republic; a cross-sectional survey. BMC Public Health 2008. doi: 10.1186/1471-2458-8-285

9. Collerton J, Davies K, \& Jagger C. Health and disease in 85 year olds: baseline findings from the Newcastle 85+ cohort study. BMJ 2009. doi: 10.1136/bmj.b4904

10. Doubova Dubova SV, Pérez-Cuevas R, Espinosa-Alarcón P, \& Flores-Hernández S. Social network types and functional dependency in older adults in Mexico. BMC Public Health 2010. doi: 10.1186/1471-2458-10-104

11. Beard JR, Officer A, de Carvalho IA, et al. The World report on ageing and health: a policy framework for healthy ageing. Lancet 2016; 387: 2145-54.

12. Jewson N. Family, Community and Health. Sociology of Health and Health Care, London: Blackwell Science 1993; 173-88.

13. Baker D, Gottschalk M, Eng C, Weber S, Tinetti M. The Design and Implementation of a Restorative Model for Home Care. The Gerontologist 2011; 41: 257-63.

14. Nadash P, Hollander Feldman P. The Effectiveness of a "Restorative" Model of Care for Home Care Patients. Home Healthcare Nurse 2003, 21: 421-23.

15. Jagger C, Collerton JC, Davies K. Capability and dependency in the Newcastle 85+ cohort study. Projections of future care needs. BMC Geriatr 2011. doi: 10.1186/1471-2318-11-21

16. Cairl RE, Pfeiffer E, Keller DM, Burke H, Samis HV. An evaluation of the reliability and validity of the Functional Assessment Inventory. J Am Geriatr Soc 1983; 31: 607-12.

17. Chiu H, Chen Y, Mau L, Shiao S, Liu H, Huang M. An evaluation of the reliability and validity of the Chinese-version OARS Multidimensional Functional Assessment Questionnaire. Chinese Journal of Public Health 1997; 16: 119-32.

18. Alcañiz M, Brugulat $P$, Guillén $M$, Medina-Bustos A, Mompart-Penina A, Solé-Auró A. Risk of dependence associated with health, social support, and lifestyle. Rev Saude Publica 2015. doi:10.1590/s0034-8910.2015049005585

19. Chokkanathan S, Mohanty J. Health, family strains, dependency, and life satisfaction of older adults. Arch Gerontol Geriatr 2017; 71: 129-35.

20. Yao Y. Weakening Family Support for the Elderly in China. Chinese Sociology \& Anthropology 2001; 34: $26-34$.

21. Leung JC. Family support for the elderly in China: issues and challenges. J Aging Soc Policy 1997; 9(3): 87-101.

22. Adhikari R, Jampaklay A, Chamratrithirong A. Impact of children's migration on health and health care-seeking behavior of elderly left behind. BMC Public Health 2011. doi: 10.1186/1471-2458-11- 
23. Montgomery RJ. The family role in the context of long-term care. J Aging Health 1999; 11: 383-416.

24. Geurtzen N, Keijsers Ger PJ, Karremans Johan C, Hutschemaekers Giel JM. Patients' care dependency in mental health care: Development of a self-report questionnaire and preliminary correlates. J Clin Psychol 2018; 74(7):1189-206.

25. Fernandez JL, Forder J. Ageing societies: challenges and opportunities. BUPA Health Pulse 2010. Available from: http://www.lse.ac.uk/businessAndConsultancy/LSEConsulting/pdf/bupa.pdf

26. Tu YC, Wang RH, Yeh SH. Relationship between perceived empowerment care and quality of life among elderly residents within nursing homes in Taiwan: a questionnaire survey. Int J Nurs Stud 2006; 43: 673-80.

27. Matthews FE, Bennett $H$, Wittenberg $R$, et al. Who lives where and does it matter? Changes in the health profiles of older people living in long term care and the community over two decades in a high income country. PLoS One 2016. doi: 10.1371/journal.pone.0161705

28. Galenkamp H, Deeg DJ, Huisman M, Hervonen A, Braam AW, Jylhä M. Is self-rated health still sensitive for changes in disease and functioning among nonagenarians? J Gerontol B Psychol Sci Soc Sci 2013; 68(5): 848-58.

29. Kingston A, Wohland $P$, Wittenberg R. et al. Is late-life dependency increasing or not? A comparison of the Cognitive Function and Ageing Studies (CFAS). Lancet 2017; 390: 1676-84.

30. Darbà J, Kaskens L. Relationship between patient dependence and direct medical-, social-, indirect-, and informal-care costs in Spain. Clinicoecon Outcomes Res 2015; 2: 387-95.

\section{Tables}




\begin{tabular}{|c|c|c|c|c|}
\hline \multirow[t]{2}{*}{ Variable categories } & \multicolumn{2}{|c|}{ Men $(N=380)$} & \multicolumn{2}{|c|}{ Women $(N=533)$} \\
\hline & $\mathrm{n}$ & $\%$ & $\mathrm{n}$ & $\%$ \\
\hline \multicolumn{5}{|l|}{ Age (yr) } \\
\hline $60-69$ & 228 & $(60.0)$ & 341 & $(64.0)$ \\
\hline $70-79$ & 131 & $(34.5)$ & 149 & $(27.9)$ \\
\hline$\geq 80$ & 21 & (5.5) & 43 & (8.1) \\
\hline \multicolumn{5}{|l|}{ Ethnicity } \\
\hline Han & 166 & $(43.7)$ & 337 & $(63.2)$ \\
\hline Ethnic minorities & 214 & $(56.3)$ & 196 & $(36.8)$ \\
\hline \multicolumn{5}{|l|}{ Marital status } \\
\hline Married & 345 & $(90.8)$ & 389 & (73.0) \\
\hline Non-married & 35 & $(9.2)$ & 144 & $(27.0)$ \\
\hline \multicolumn{5}{|l|}{ Education (yr) } \\
\hline $0-6$ & 44 & $(11.6)$ & 132 & $(24.8)$ \\
\hline $7-9$ & 163 & $(42.9)$ & 190 & $(35.6)$ \\
\hline $10-12$ & 96 & $(25.3)$ & 115 & $(21.6)$ \\
\hline $13+$ & 77 & $(20.2)$ & 96 & $(18.0)$ \\
\hline \multicolumn{5}{|l|}{ Individual income } \\
\hline$¥ 0$ to 1,999 & 232 & $(61.1)$ & 318 & (59.7) \\
\hline$¥ 2,000$ to 3,999 & 80 & $(21.1)$ & 150 & $(28.1)$ \\
\hline$¥ 4,000$ to 5,999 & 48 & $(12.6)$ & 39 & (7.3) \\
\hline$¥ 6,000$ and Over & 20 & (5.2) & 26 & (4.9) \\
\hline \multicolumn{5}{|l|}{ Smoking status } \\
\hline Yes & 118 & $(31.1)$ & 8 & (1.5) \\
\hline No & 262 & $(68.9)$ & 525 & $(98.5)$ \\
\hline \multicolumn{5}{|l|}{ Alcohol use } \\
\hline Yes & 146 & $(38.4)$ & 40 & (7.5) \\
\hline No & 234 & (61.6) & 493 & (92.5) \\
\hline
\end{tabular}




\begin{tabular}{|lllll|}
\hline Yes & & & & \\
\hline No & 130 & $(34.2)$ & 230 & $(43.2)$ \\
\hline Chronic disease status & & & & \\
Yes & 250 & $(65.8)$ & 303 & $(56.8)$ \\
No & 259 & $(68.2)$ & 352 & $(66.0)$ \\
\hline Dependence status & 121 & $(31.8)$ & 181 & $(34.0)$ \\
\hline Yes & 39 & $(10.3)$ & 77 & $(14.4)$ \\
\hline No & 341 & $(89.7)$ & 456 & $(85.6)$ \\
\hline
\end{tabular}

\begin{tabular}{|lllll|}
\hline \multicolumn{4}{|l}{ Table 2. The odds ratios of social resources levels for dependency status by logistic regression model } \\
\hline Variables & Odds Ratios & $95 \%$ Confidence lnterval & $p$-Value \\
\hline Social resources & 0.78 & 0.73 & 0.84 & $<0.001$ \\
\hline Age & 1.02 & 0.99 & 1.05 & 0.229 \\
\hline Gender & 1.29 & 0.79 & 2.11 & 0.314 \\
\hline Chronic disease status & 1.38 & 0.87 & 2.20 & 0.174 \\
\hline Individual income & 0.94 & 0.67 & 1.32 & 0.737 \\
\hline Education levels & 0.99 & 0.77 & 1.27 & 0.942 \\
\hline Physical activity & 0.84 & 0.52 & 1.36 & 0.479 \\
\hline Marital status & 0.83 & 0.65 & 1.07 & 0.151 \\
\hline Smoking status & 0.69 & 0.31 & 1.52 & 0.355 \\
\hline Alcohol use & 0.79 & 0.41 & 1.53 & 0.486 \\
\hline
\end{tabular}


Table 3. The $\beta$ Coefficients of different dimensions of social resources for dependency score and important independent variables from multiple regression analysis

\begin{tabular}{|llll|}
\hline Variables & $\beta$ & SE & $p$-Value \\
\hline Social support & -3.69 & 0.32 & $<0.001$ \\
\hline Social communication & 0.15 & 0.30 & 0.625 \\
\hline Family support & -0.59 & 0.51 & 0.255 \\
\hline Interpersonal relationship & 0.52 & 0.49 & 0.294 \\
\hline Chronic disease status & 3.61 & 0.82 & $<0.001$ \\
\hline Individual income & -1.81 & 0.58 & 0.001 \\
\hline Gender & -1.91 & 0.90 & 0.034 \\
\hline Education levels & -1.13 & 0.46 & 0.014 \\
\hline Physical activity & -2.04 & 0.89 & 0.022 \\
\hline Age & 0.06 & 0.06 & 0.293 \\
\hline Marital status & 0.13 & 0.45 & 0.760 \\
\hline Smoking status & -0.85 & 1.28 & 0.505 \\
\hline Alcohol use & -1.88 & 1.12 & 0.095 \\
\hline
\end{tabular}

$\beta$ : standardized regression coefficient

SE: standard error 


\begin{tabular}{|c|c|c|c|c|}
\hline \multirow[t]{2}{*}{$\begin{array}{l}\text { Variable } \\
\text { categories }\end{array}$} & \multirow[t]{2}{*}{ Variable description } & $\begin{array}{l}\text { Dependence } \\
\text { score }\end{array}$ & \multirow[t]{2}{*}{ SE } & \multirow[t]{2}{*}{$p-$} \\
\hline & & Mean & & \\
\hline \multicolumn{5}{|c|}{ Chronic disease } \\
\hline Group 1 & $\begin{array}{l}\text { Chronic disease }(+) \text {, Social support } \\
(-)\end{array}$ & 50.43 & 0.84 & \\
\hline Group 2 & Chronic disease (-), Social support (-) & 45.94 & 1.29 & 0.003 \\
\hline Group 3 & $\begin{array}{l}\text { Chronic disease }(+) \text {, Social support } \\
(+)\end{array}$ & 42.17 & 0.58 & 0.008 \\
\hline Group 4 & $\begin{array}{l}\text { Chronic disease }(-) \text {, Social support } \\
(+)\end{array}$ & 38.71 & 0.80 & $<0.001$ \\
\hline \multicolumn{5}{|c|}{$P$ for trend $<0.001$} \\
\hline \multicolumn{5}{|c|}{ Individual income } \\
\hline Group 1 & Low income, Social support (-) & 50.47 & 0.97 & \\
\hline Group 2 & High income, Social support (-) & 47.23 & 1.17 & 0.040 \\
\hline Group 3 & Low income, Social support (+) & 42.22 & 0.66 & $<0.001$ \\
\hline Group 4 & High income, Social support (+) & 38.99 & 0.85 & 0.005 \\
\hline \multicolumn{5}{|c|}{$P$ for trend $<0.001$} \\
\hline
\end{tabular}

Covariates included in the analysis of covariance were age, gender, education levels, physical activity, marital status, smoking status and alcohol use.

\section{Supplementary Files}

This is a list of supplementary files associated with this preprint. Click to download.

- Questionnaire.doc 